\title{
Type 2 Diabetes Mellitus Risk Level, Cardiovascular Diseases Risk Level, and Quality of Work Life among University Staffs; Correlational Study
}

\author{
Titis Kurniawan, Eka Afrimasari, Sri Hartati P \\ Faculty of Nursing, Universitas Padjadjaran \\ Email:t.kurniawan@unpad.ac.id/t.kurniawan1981@gmail.com
}

Submitted: 7-12-2018 Accepted: 24-7-2018 Published: 10-8-2018

\begin{abstract}
Type 2 diabetes mellitus and cardiovascular diseases are two of the most serious health problems produce wide negative impacts in Indonesia. Both diseases shares similar risks factors and may affect individual's health status and quality of work (QoWL). Unfortunately, there is no evidence reported the chronic diseases risk level and their correlation with QoWL among university staffs in Indonesia. This correlational study aimed to identify the risk level of Type 2 diabetes mellitus (T2DM) and cardiovascular diseases and it correlation with the QoWL among university staffs. As many as 125 university staffs from one of public university in West Java - Indonesia were recruited randomly and asked to complete Finnish Diabetes Risk-Assessment form, The Jakarta Cardiovascular Scale, and quality of work life (QoWL) Evaluation Scale. The collected data were analyzed using descriptive and Pearson Correlation test. Results showed that nearly half of respondents had chronic diseases risk elevation; T2DM (40.39) and cardiovascular diseases (49\%). Additionally, more than half of them $(52.40 \%)$ perceived that their QoWL was less satisfied. It was found there was a significant relationship between T2DM risk level and cardiovascular diseases risk $(r=0.513 ; p=0.00)$; however, there was no significant correlation, neither between T2DM risk level $(\mathrm{p}=0.54)$ nore cardiovascular disease risk level $(\mathrm{p}=0.19)$ with QoWL. To summarize, the university staffs are vulnerable for developing chronic diseases and have less satisfied QoWL. Therefore, it is important for the university to develop policy or program that enhances the employees' opportunity in managing the risk and improving their health status and QoWL.
\end{abstract}

Keywords: Cardiovascler-diseases, diabetes-mellitus, QoWL, risk- level. 
Titis Kurniawan: Type 2 Diabetes Mellitus Risk Level, Cardiovascular Disease Risk Level

\section{Introduction}

Non-communicable diseases (NCDs) currently emerge as one of serious health problem worldwide, including Indonesia. This typical disease reported as the leading global cause of death and is responsible for $70 \%$ death worldwide, and the number is continously growing (World Health Organization [WHO], 2017). Nationally, the number of patients with chronic disease reported as the top ten highest deathcaused-diseases in Indonesia (Ministery of Health Republic of Indonesia [MOHRI], 2013). Other survey reported $73 \%$ death in Indonesia related to NCDs (WHO, 2017). Cardiovascular diseases and diabetes mellitus in particular were noted closely related to premature death and disabilities (WHO, 2014).

These burdens may be minimized, particularly by performing healthy lifestyle including regular physical activity, healthy diet, and smoking cessation. Those recommended lifestyle are identified effectively minimizing the risk of both chronic diseases (Tuomelehto, Schwarz, \& Lindstrom, 2011; Vartiainen, Jousilahti, Alfthan, Sundvall, Pietinen, \& Puska, 2000; Zatonski \& Willett, 2005). Unfortunately, a survey found that some risk factors of chronic diseases exist among Indonesian population. It was reported that $35 \%$ of total population were actively smoking, $27.8 \%$ raised blood pressure, and $4.8 \%$ obesity (WHO, 2014).

Those trends also identified among university staffs. One study in Barbados found that university staff who older than 45 years old identified have atleast one of chronic diseases risk factors (smoking, lack of physical activity, obesity, lack of vegetables and fruits consumption, and raised blood pressure) and more than half of them have all three risk factors (Morris, Unwin, Ali, Brathwaite-Graham, Samuels, 2011). Almost similar findings identified in one study conducted among staffs of one university in Saudi Arabia (Alzeidan R, Rabiee F, Mandil A, Hersi A, \& Fayed A, 2016). In Indonesian context, a study identified that family history and gender as significant hypertensionassociated risk factors among staffs in one public university in West Java (Azra,
2016). Moreover, prevention program still challenging.

It was generally being understood that work types and working environment are the important health determinants. International Labor Organization [ILO] (2008) reported that 2.3 milion deaths worldwide were associated with work, 321.000 deaths were occupational-accident related death and the rest were related to the work-related diseases. Additionally, it noted that employees who reported lack of physical activities, actively smoking and obesity were associated with an increase of health care charges (Kuriyama, Hizawa, Ohmori, Suzuki, Nishino, Fujita, et. al., 2004). Moreover, these typical employees created higher disease burden and absenteeism compared with those who did not have risk factors (Asay, Roy, Lang, Payne, \& Howard. 2016; Kolbe-Alexander, Buckmaster, Nossel, Dreyer, Bull, Noakes, et al., 2008). In the other words, having chronic diseases risks will potentially lessen employees' productivity and quality of work. The impact may greater when the staffs already developed the chronic diseases. Absenteeism, low productivity, physical and psychological problem as well as severe fatigue that potent to develop work disability were commonly experienced by staffs who suffer from chronic diseases (Fouad, Waheed, Gamal, Amer, Abdellah, \& Shebl, 2017; Varekamp \& van-Dijk, 2010; Vuong, Wei, \& Beverly, 2016).

Staffs productivity and quality of work life (QoWL) are two variables that positively associated (Hatam, Zarifi, Lotfi, Kavosi, \& Tavakoli, 2014). QoWL also positively related to work performance and career advancement among academic staffs (Acheampong, Muhammed, \& Agyapong, 2016; Parsa, Khairudin Bin Idris, Bahaman Bin Abu Samah, Nor Wahiza Binti Abdul Wahat, Parsa, 2014). However, there were no published article suggested the correlation between having risk for chronic diseases status and QoWL. Therefore, it is important to identify both variables and its correlation to early detect the potential burdens as well as enlarge the opportunity for preventing the diseases as part of health status and QoWL improvement. 
Titis Kurniawan: Type 2 Diabetes Mellitus Risk Level, Cardiovascular Disease Risk Level

\section{Methods}

This study applied descriptive correlational design and conducted in one public university in West Java - Indonesia. Data collection was conducted in three faculties. After the researcher team gained the permission letter from each faculty, the faculty will announce to the staffs that our team will conduct research where free general physical health assessment (blood glucose test, measuring blood pressure, and body mass index) as one of the benefits for staff who participated in this study. There were 125 staffs $(34.25 \%$ of total population 365 staffs) that voluntarily attend the invitation, provided informed consent, and fill the data requested.

Type 2 Diabetes Mellitus (T2DM) risk level was measured using Finnish Diabetes Risk Assessment Form developed by Lindström and Tuomilehto (2003). It was specifically developed to measure the risk level of T2DM based on the reslt of accumulated score of diabetes risk factors including age, body mass index (BMI), waist circumference, physical activity, daily vegetable and fruit consumption, history of hypertension medication, hyperglycemia history, and diabetes family history. The results were categorized into low risk - 1 in 100 persons will develop diseases (total score $<7$ ), slightly elevated- 1 in 25 persons will develop diseases (total score 7-11); moderate risk -1 in 6 persons will develop diseases (total score 12-14), high risk - 1 in 3 persons will develop diseases (total score 15-20) and very high risk-1 in 2 persons will develop diseases (total score $>20$ ) (Lindström \&Tuomilehto, 2003).

The Skor Kardiovakular Jakarta (SKJ), developed by Kusuma (2014), was applied for measuring the cardiovascular diseases risk level. This measurement was modified from Framingham Risk Score (FRS) that commonly used to identify cardiovascular diseases (CVD) risk level over 10 years based on the accumulated score of cardiovascular risk factors including hypertension hyistory, age, blood high-density lipoprotein (HDL) level, smoking history, blood total cholesterol level, and diabetes history. Different with FRS, SKJ did not use blood HDL and blood total cholesterol level for counting the risk level and replaced it by physical activity and body mass index (BMI) (Kusuma, 2014; MOHRI, 2017). Both measurements were reported as valid, reliable, and applicable to measure both variable (Janghorbani, Adineh, \& Amini, 2013; Lindström J \& Tuomilehto J., 2003; Kusuma, 2014).

Since some data (such as hyperglycemia history, waist circumeference, blood pressure, and body mass index) considered as uncommonly known by respondents, those were assessed by performing direct physical examination. Hyperglycemia in this study was measured based on the finger prick blood glucose test. The result of total score was categorized into low risk - risk for CVD $<10 \%$ (total score -7 to 1 ), moderate risk risk for CVD $10-20 \%$ (total score 2-4) and high risk - risk for CVD > 20\% (total score > 5) (Kusuma, 2014).

Data related Quality of Work Life (QoWL) were collected using QoWL Evaluation scale developed by Timosi, Pedroso, de-Francisco, and Pillati (2008). It consisted of 9 domains (work environment, organization culture and climate, relation and co-operation, training and development, compensation and rewards, facilities, job satisfaction and security, work autonomy, and adequacy of resources) as well as 50 items with five answer options; very satisfied (5) to very unsatisfied (1). This claimed as valid and reliable with Chronbach alpha score higher than 0.6 (Swamy, Nanjundeswaraswamy, \& Rashmi, 2015). Higher total score indicated the higher QoWL.

Descriptive analysis was conducted to describe each variable including respondent characteristics, and further analysis was conducted for identifying the correlation between the identified variables by operating Pearson correlation test.

\section{Results}

\section{Respondents' Characteristics}

Generally, most of respondents $(86.36 \%)$ are married, more than half of them $(55.20 \%)$ are male, and almost of half of them (49.6\%) are in the vulnerable age for developing chronic diseases. The detaile data related the respondents characteristics are listed in the 
Titis Kurniawan: Type 2 Diabetes Mellitus Risk Level, Cardiovascular Disease Risk Level table bellow:

Table 1 Respondents Characteristics $(n=125)$

\begin{tabular}{cccc}
\hline & Characteristics & f & \% \\
\hline Gender & Male & 69 & 55.20 \\
& Female & 56 & 44.80 \\
Age (years) & $>45$ years older & 62 & 49.6 \\
Mean +SD $(43.26+$ & $<45$ years old & 63 & 50.4 \\
Marital Status & Married & 114 & 91.20 \\
& Not Married Yet & 8 & 6.40 \\
& Widow/Widower & 2 & 1.60 \\
Educational Level & Not Fill The Data & 1 & 0.80 \\
& Elementary school & 3 & 2.4 \\
& Junior high school & 4 & 3.2 \\
& Senior high school & 22 & 17.60 \\
& Diploma and bachelor & 40 & 32.00 \\
& Master & 29 & 23.20 \\
& Doctor & 22 & 17.60 \\
& Not Fill The Information & 5 & 4.00 \\
\hline
\end{tabular}

Table 2 Health Characteristics and Prevention Behaviors $(n=125)$

\begin{tabular}{|c|c|c|c|}
\hline \multicolumn{2}{|c|}{ Health Characteristics and Behaviors } & f & $\%$ \\
\hline \multirow[t]{2}{*}{ Blood Cholesterol level } & Normal $(<200 \mathrm{mg} / \mathrm{dl})$ & 56 & 44.80 \\
\hline & Hypercholesterolemia & 69 & 55.20 \\
\hline \multirow[t]{2}{*}{ Blood glucose level } & Normal & 115 & 92.00 \\
\hline & Hyperglycemia & 10 & 8.00 \\
\hline \multirow[t]{2}{*}{ Waist circumference } & Normal & 78 & 63.40 \\
\hline & Higher than normal & 47 & 37.60 \\
\hline \multirow[t]{3}{*}{ BMI (Body mass index) } & Normal & 52 & 41.60 \\
\hline & Overweight & 45 & 36.00 \\
\hline & Obesity & 28 & 22.40 \\
\hline \multirow{2}{*}{$\begin{array}{l}\text { Blood cholesterol check } \\
\text { experience }\end{array}$} & Ever & 67 & 53.60 \\
\hline & Never & 58 & 46.40 \\
\hline \multirow{2}{*}{$\begin{array}{l}\text { Blood glucose check } \\
\text { experience }\end{array}$} & Ever & 42 & 33.06 \\
\hline & Never & 83 & 66.94 \\
\hline \multirow[t]{2}{*}{ Smooking } & Yes & 26 & 19.26 \\
\hline & No & 99 & 80.74 \\
\hline \multirow{2}{*}{$\begin{array}{l}\text { Daily vegetables and } \\
\text { Fruits consumption }\end{array}$} & Yes & 96 & 72.72 \\
\hline & No & 29 & 27.28 \\
\hline \multirow[t]{2}{*}{ Routine physical activities } & Yes & 71 & 53.79 \\
\hline & No & 54 & 46.21 \\
\hline
\end{tabular}


Titis Kurniawan: Type 2 Diabetes Mellitus Risk Level, Cardiovascular Disease Risk Level

Table 3 Type 2 Diabetes Mellitus (T2DM) and Cardiovascular (CVD) Risk Level $(n=125)$

\begin{tabular}{|c|c|c|c|}
\hline \multicolumn{2}{|c|}{ Chronic Diseases Risk Level } & f & $\%$ \\
\hline \multirow[t]{5}{*}{ T2DM Risk Level } & $\begin{array}{l}1 . \quad \text { Low risk (score } \\
0-7=1 \text { in } 100 \text { persons } \\
\text { will develop diseases) }\end{array}$ & 80 & 60.61 \\
\hline & $\begin{array}{l}2 . \quad \text { Slightly elevated } \\
\text { risk (scor } 7-11=1 \text { in } \\
25 \text { persons will develop } \\
\text { diseases) }\end{array}$ & 41 & 31.06 \\
\hline & $\begin{array}{l}\text { 3. Moderate risk } \\
\text { (score } 12-14=1 \text { in } \\
6 \text { persons will develop } \\
\text { diseases) }\end{array}$ & 10 & 7.58 \\
\hline & $\begin{array}{l}4 . \quad \text { High risk (score } \\
15-20=1 \text { in } 3 \text { persons } \\
\text { will develop diseases) }\end{array}$ & 1 & 0.75 \\
\hline & $\begin{array}{l}5 . \quad \text { Very high risk } \\
\text { (score }>20=1 \text { in } 2 \\
\text { persons will develop } \\
\text { diseases) }\end{array}$ & 0 & 0.00 \\
\hline \multirow[t]{3}{*}{ CVD Risk Level } & $\begin{array}{l}\text { Low risk (score }-7 \text { to } 1) \sim \\
\text { risk for developing CVD } \\
<10 \%\end{array}$ & 67 & 50.75 \\
\hline & $\begin{array}{l}\text { Moderate risk (score; } \\
2-4 \text { ) } \sim \text { risk for CVD } 10 \\
-20 \%\end{array}$ & 38 & 28.79 \\
\hline & $\begin{array}{l}\text { High risk }(\text { score }>5) \sim \\
\text { risk for } C V D>20 \%\end{array}$ & 27 & 20.46 \\
\hline
\end{tabular}

Table 4 University Staffs' Quality of Work Life

\begin{tabular}{lccc}
\hline \multicolumn{1}{c}{ Variable \& Domain } & Mean & \multicolumn{2}{c}{ Frequency (\%) } \\
\cline { 3 - 4 } & & $\begin{array}{c}\text { Unsatisfied (Low } \\
\text { QoWL) }\end{array}$ & $\begin{array}{c}\text { Satisfied/ } \\
\text { (High QoWL) }\end{array}$ \\
\hline QoWL (score range 50 - 250) & 127.29 & $66(52.40)$ & 60 (47.60\%) \\
Work environment Domain (6 items) & 2.62 & & \\
Organization culture Domain (7 items) & 2.61 & & \\
Relationship Domain (6 items) & 2.58 & \\
Training and development Domain (4 & 2.33 & \\
items) & & \\
Compensation and rewards Domain (5 & 2.54 & \\
items) & & \\
Facilities Domain (5 items) & 2.53 & \\
Job satisfaction and security Domain (8 & 2.50 & \\
items) & & \\
Work autonomy Domain (6 items) & 2.59 & \\
Adequacy of resources Domain (3 items) & 2.57 & \\
\hline
\end{tabular}


Titis Kurniawan: Type 2 Diabetes Mellitus Risk Level, Cardiovascular Disease Risk Level

Table 5 Correlation between Type 2 Diabetes Mellitus (T2DM) Risk Level, Cardiovascular Diseases (CVD) Risk Level and Quality of Work Life (QoWL)

\begin{tabular}{lccc}
\hline & T2DM & CVD risk score & QoWL score \\
T2DM risk score & - & $\mathrm{r}=0.513$ & $\mathrm{r}=-0.06$ \\
& & $\mathrm{p}=0.000$ & $\mathrm{p}=0.54$ \\
CVD risk score & - & - & $\mathrm{r}=-0.12$ \\
& & & $\mathrm{p}=0.19$ \\
QoWL score & - & - & - \\
\hline
\end{tabular}

Additionally, it was identified that more than half of repondents reported that ever check their blood cholesterol level $(53.6 \%)$, performed routin physical activities $(53.79 \%)$, daily consumed vegetables and fruits $(72.27 \%)$, and did not actively smoking (80.74\%). However, more than half of respondents $(55.2 \%)$ had hypercholesterolemia, more than one-third overweight $(36 \%)$, waist circumference higher than normal (central obesity) (37.6\%), and never check blood glucose level before participated in this study $(66.94 \%)$. The complete data were listed in the table bellow.

Morover, it was found that more than onethird of staffs identified being vulnerable for developing a typical chronic diseases, either Type 2 Diabetes Mellitus (score > 7) or cardiovascular diseases (score $>2$ ). The complete risk level categories are listed in the table bellow.

In terms of QoWL, the given table described that more than half of respondents reported less satisfied/low QoWL $(52.40 \%)$. It is indicated that staffs required some improvements, particularly in the training and development domain that found with lowest score.

The table signified there was significant positive relationship between T2DM and CVD risk level, means that higher risk for T2DM will produce higher risk for CVD and oppositely. Additionally, both diseases risk levels were not significant relationsip with QoWL.

\section{Discussion}

This study found that almost half of respondents had elevated risk for developing chronic diseases, either T2DM or CVD.
These findings strengthen trends found in previous studies that risk for T2DM and CVD also exist among university staffs. Hypercholesterolemia $\quad(55.20 \%)$ and abnormalbody mass index $(58.40 \%)$ identified as identified risk factors with the highest percentage. Additionally, more than onethird of respondents had waist circumference higher than normal $(37.6 \%)$. These should be carefully considerejmmd since some studies noted that hypercholesterolemia, general and central obesity closely related to hypertension, atherosclerosis, metabolic syndrome, diabetes and cardiovascular diseases (Barroso, Marins, Alves, Gonçalves, Barroso, \& Rocha, 2017; Hirani, Zaninotto, \& Primatesta, 2007; Kearn, Dee, Fitzgerald, Doherty, \& Perry, 2014; Kusuma, 2002; Memish, ElBcheraoui, Tuffaha, Robinson, Daoud, Jaber, et al., 2014). Hypercholesterolemia risk here is worsened by the respondents who reported never examined their blood cholesterol level that increase undetectable problem.

Regarding the CVD risk level, this study found higher level of risk among university staffs compared with the study conducted in Saudi Arabia. In this study, almost half of respondents $(49.25 \%)$ projected to have $>$ $10 \%$ risk for developing CVD within the next 10 years compare to $25 \%$ found in the study conducted in Saudi Arabia (Alzeidan et al., 2016). Age of the respondent paricipated is one of the reasons causing this different. In this study, the average age is older (43 years old) than that in Saudia Arabia (39 years old). As commonly known that older age are closely related to higher risk for chronic diseases, including CVD (Ekpenyong, Akpan, Ibu, \& Nyebuk, 2012; Kusuma, 2014; Yu, Ma, Yang, Pang, Yu, Tao et., al., 2015).

Even though the majority of respondents identified in the low risk level of T2DM 
Titis Kurniawan: Type 2 Diabetes Mellitus Risk Level, Cardiovascular Disease Risk Level

and CVD, this level will almost certainly increase because of the respondents' age. In the other words, respondent in any risk category will possibly move to the higher/ worse risk level because of their age addition. This trend will be worsened if the individual do not performing any recommended actions to lessen the identified risk factors. It is commonly known that older age is one of the significant risk factors for chronic diseases, either T2DM or CVD (Ekpenyong, Abdulghani H. Al-Saeed, Constantino, Molyneaux, D'Souza, Limacher-Gisler, Luo et. al., 2016; Ekpenyong et al., 2011; Kusuma, 2014; Lindström \&Tuomilehto, 2003; Yu et al., 2015).

These identified risk factors also invite institution concern because their potent to increase the next future health care charges, absenteeism, and low staffs' productivity (Kolbe-Alexander et al., 2008; Kuriyama, et. al., 2004). This condition will produce higher burdens when the staffs develop chronic diseases (Fouad et al., 2017; Varekamp et. al., 2010; Vuong et al., 2016).

Not only identified the exsiting risk factors separatedly (smooking, obesity, vegetables/ fruits consumption, blood pressure, and physical activities) as did in the previous studies (Alzeidan, et al., 2016; Azra, 2016; Morris et al., 2011), this study calculated the score and interpreted those into the particular diseases vulnerability level. It probably provides beneficial issues. Firstly, the scoring and risk level categorization may provide clearer interpretation regarding the diseases vulnerability prediction. For instant, low risk for T2DM interpreted there is 1 in 100 persons will develop T2DM, slightly elevated risk level mean 1 in 25 persons will develop T2DM, and so forth (Lindström \& Tuomilehto, 2003). Similarly, in CVD risk level where low risk level infers the individual's vulnerability for developing CVD over the 10 years is $10 \%$, moderate risk level predict the individual's vulnerability is $10-20 \%$, and so on (Kusuma, 2014).

Secondly, the scoring and risk level categorization may beneficial for formulating the recommended follow up actions. The important steps after the screening (early detection) are formulating follow up actions. The preventing actions are mostly provided in general recommendation including managing diet, body weight, smoking cessation, and performing physical exercise. In some conditions, these recommendations may failure to accommodate the urgent requirement for medical examination particularly for them who identified in high/ very high risk level category (MOHRI, 2014). Different with previous studies suggested that the respondents mostly lack of physical activity and less consume vegetables and diet, this study found the contrary trend. Regarding theses risk factors, most of respondents in this study considered not vulnerable for developing chronic diseases; they reported regular physical exercise and consume fruits and vegetables. The policy related the routine exercise schedule every Friday morning may contribute to the trend. Some faculties where the respondents work in also have additional schedule for group exercise such as badminthon, zumba, etc. Additionally, population in this study lived in the Sundanese culture area that culturally Sundanese food is complentarily with fresh vegetables ("lalapan") and fruits.

Regarding Quality of Worklife [QoWL], more than half of respondents in this study reported less satisfied (low) QoWL, where training and development found as lowest score domain. It is indicated that most of staffs invite improvement actions from management with widening opportunity for training and development as the priority ones. This finding invite the management concern since previous study suggested that low QoWL closely related to work productivity, career development, work performance, commitment and work satisfaction (Acheampong et al., 2016; Hatam et al., 2014; Mirkamali \& Thani, 2011; Normala, 2010). Additionally, it is recommended for management to start improvement either for resulted products or provided services by improving the staffs' QoWL (Narehan, Haerunnisa, Razak, \& Lapok; 2014).

Additional analysis found there was a significant positive relationship between T2DM risk level and CVD risk level, but there was no significant relationship between both risk levels with QoWL. It indicates that higher risk for T2DM will cause higher risk for CVD and vise versa. These strengthen 
Titis Kurniawan: Type 2 Diabetes Mellitus Risk Level, Cardiovascular Disease Risk Level

previous findings suggested that both diseases shared similar risk factors (age, blood pressure, body mass index). It also infers that controlling those similar risk factors will together lessen both diseases risk level (Martín-Timón, Sevillano-Collantes, SeguraGalindo, \& delCañizo-Gómez, 2014).

Neither T2DM nore CVD risk level is associated with QoWL. These findings possibly caused by the risk factor identified here were the conditions that actually "healthy" conditions. Having raised blood pressure, abnormal body weight, lack of psysical activities, as well as vegetable and fruits consumption are not significantly inhibit idividuals in performing work. Moreover, work performance and work satisfaction that may closely related to the diseases risk level are only parts of the QoWL domains measured in this study.

The evidences signify that improving both, either QoWL or diseases risk level will potentially beneficial either for staffs or the institution (Acheampong et al., 2016; Hatam et al., 2014; Kolbe-Alexander et al., 2008; Kuriyama et al., 2004; Parsa et al., 2014). However, this study suggested that improving QoWL may not directly improve diseseas risk level and oppositely. It also infers that important for the university management to develop separate program, either in lowering diseases risk level or in improving QoWL.

\section{Research Limmitation}

The main limitation of this study is the participation rate that considered low $(34.25 \%)$ compared with the population targeted. It cause the findings could not be generalized to the overall university.

\section{Conclusion}

This study aimed to identify the risk level of T2DM, CVD, and QoWL as well as the relationship between those variables. Generally, almost half of respondents had elevated risk level either for developing T2DM or CVD as well as lees satisfied QoWL. Additionally, there is a significant positive relationship between risk level of T2DM and CVD. Moreover, there is no significant relationship between both diseases risk level with QoWL. It indicates that lessening T2DM risk level will also beneficial in reducing CVD risk level but may not directly enhancing QoWL.

Eventhough there was no correlation between diseases risk level and QoWL, improving all of them are beneficial either for staffs or institution. It is important for university management to develop worksite health promotion program in order to improve the staffs' opportunities in managing their identified diseases risk factors. This program could be initiated by intensifying the existing exercise program either in the faculty or university level. Additionally, university management also recommended enhancing the staffs' opportunity in accessing training and development program such as by conducting inhouse training as part of the QoWL improvement program.

\section{References}

Acheampong, A., Muhammed, M.A., \& Agyapong, K. (2016). Perceived quality of work life and work performance among university academic staff. International Journal of Current Research and Academic Review, 4(4), 1-13. https://doi.org/10.20546/ ijcrar .2016.404.001.

Alzeidan, R., Rabiee, F., Mandil, A., Hersi, A., \& Fayed, A. (2016). Non-communicable disease risk factors among employees and their families of a Saudi University: An epidemiological study. Plos One, 11(11), e0165036. https://doi.org/10.1371/journal. pone. 0165036 .

Asay, G.R.B., Roy, K., Lang, J.E., Payne, R.L., \& Howard, D.H. (2016). Absenteeism and employer costs associated with chronic diseases and health risk factors in the US workforce. Prev Chronic Dis, 13, 150503. DOI: http://dx.doi.org/10.5888/ pcd13.150503.

Azra, M.J. (2016). Prevalensi dan faktor risiko hipertensi pada Pegawai Rektorat Institute Pertanian Bogor (Prevalence 
Titis Kurniawan: Type 2 Diabetes Mellitus Risk Level, Cardiovascular Disease Risk Level

and hypertension risk factor among Bogor Agriculture Institute Rectorat Staffs). Retrieved from http://repository.ipb.ac.id/ jspui/bitstream/123456789/86474/1/I16jma. pdf.

Barroso, T.A., Marins, L.B., Alves, R., Gonçalves, A.C.S., Barroso, S.G., \& Rocha, G.S. (2017). Association of central obesity with the incidence of cardiovascular diseases and risk factors. International Journal of Cardiovascular Science, 30(5), 416-424.

Ekpenyong, C.E., Akpan, U.P., Ibu, J.O., \& Nyebuk, D.E. (2012). Gender and age specific prevalence and associated risk factors of type 2 diabetes mellitus in Uyo Metropolis, South Eastern Nigeria. Diabetologia Croatica, 411.

Fouad, A., Waheed A., Gamal, A., Amer, S.A.A.M., Farouk, R., \& Shebl, F.M. (2017). Effect of chronic diseases on work productivity: A propensity score analysis. Journal of Occupational Environmental Medicine, 59(5), 480-485. DOI: 10.1097/ JOM.0000000000000981.

Hatam, N., Zarifi, M., Lotfi, M., Kavosi, Z., \& Tavakoli, A. (2014). The relationship between quality of work life and human resource productivity in knowledge workers. Journal of Health Mananagement \& Informatics, I(3), 59-65.

Hirani, V., Zaninotto, P., \& Primatesta, P. (2007). Generalised and abdominal obesity and risk of diabetes, hypertension and hypertension-diabetes co-morbidity in England. Public Health Nutrition, 11(5), 521527. DOI: $10.1017 / \mathrm{S} 1368980007000845$.

International Labor Organization [ILO]. (2008). 18th International Conference of Labour Statisticians. Retreived from http://www.ilo.org/wcmsp5/groups/ public/@dgreports/@stat/documents/ meetingdocument/wcms_101467.pdf.

Janghorbani, M., Adineh, H., \& Amini, M. (2013). Evaluation of the finnish diabetes risk score (FINDRISC) as a screening tool for the metabolic syndrome. The Review of Diabetic
Studies, 10(4), 283-292. doi: 10.1900/ RDS.2013.10.283.

Kearn, K., Dee, A., Fitzgerald, A.P., Doherty, E., \& Perry, I.J. (2014). Chronic disease burden associated with overweight and obesity in Ireland: The effects of a small BMI reduction at population level. BMC Public Health, 14, 143.

Kolbe-Alexander, T.L., Buckmaster, C., Nossel, C., Dreyer, L., Bull, F., Noakes, T.D., et al. (2008). Chronic disease risk factors, healthy days and medical claims in South African employees presenting for health risk screening. BMC Public Health, 8, 228. DOI:10.1186/1471-2458-8-228.

Kuriyama, S., Hozawa, A., Ohmori, K., Suzuki, Y., Nshino Y., Fujita K., et al. Joint impact of health risks on health care charges: 7-year follow-up of National Health Insurance beneficiaries in Japan (the Ohsaki Study). Preventive Medicine, 39, 1194-1199.

Kusuma, D., (2002). The influence of smoking cessation, regular physical exercise and/ or physical activity on survival: A 13 years cohort study of the Indonesian population in Jakarta. Medical Journal of Indonesia, 11(4), $230-242$.

Lindström, J., \&Tuomilehto, J. (2003). The diabetes risk score. Diabetes Care, 26(3), 725-31.

Martín-Timón, I., Sevillano-Collantes, C., Segura-Galindo, A., \& del Cañizo-Gómez, F.J.(2014). Type 2 diabetes and cardiovascular disease: Have all risk factors the same strength?. World Journal of Diabetes, 5(4), 444-470.

Memish, Z.A., El Bcheraoui, C., Tuffaha, M., Robinson, M., Daoud, F., Jaber, S., et al. (2014). Obesity and associated factors Kingdom of Saudi Arabia, 2013. Preventing Chronic Diseases, 11, 140236. DOI: http:// dx.doi.org/10.5888/ pcd11.140236.

Ministery of Health Republic of Indonesia [MOHRI]/Kementerian Kesehatan RI (2013). Basic Health Research 2013 (Riset Kesehatan 
Titis Kurniawan: Type 2 Diabetes Mellitus Risk Level, Cardiovascular Disease Risk Level

Dasar 2013). Retrieved 14 January 2018 from http://www.depkes.go.id/resources/ download/general/Hasil\%20Riskesdas $\% 20$ 2013.pdf.

., (2017). Technical guideline cardiovascular diseases management for physician (Petunjuk teknis penatalaksanaan penyakit kardiovaskular untuk dokter). Retrieved from http://www.puskeshaji. depkes.go.id/assets/doc img/330f63c60ccea df987827a397a91197b.p.pdf.

Mirkamali, S.M., \& Thani, F.N., (2011). A study on the Quality of Work Life (QWL) among faculty members of University of Tehran (UT) and Sharif university of Technology (SUT). Procedia - Social and Behavioral Sciences, 29, 179 - 187.

Morris, E., Unwin, N., Ali, E., BrathwaiteGraham, L., \& Samuels, T.A. (2011). Chronic non-communicable disease risk factor survey 2010 among University of the West Indies staff at Cave Hill, Barbados. West Indian Medical Journal, 60(4), 452-8.

Narehan, H., Hairunnisa, M., Razak, A.N., Lapok, F. (2014). The effect of Quality of Work Life (QWL) programs on Quality of Life (QOL) among employees at multinational companies in Malaysia. Procedia-Social and Behavioral Sciences, 112, 24-34.

Normala, D. (2010). Investigating the relationship between quality of work life and organizational commitment amongst employees in Malaysian firms. International Journal of Business and Management, 5, 75.

Parsa, B., Khairudin Bin Idris, Bahaman Bin Abu Samah, Nor Wahiza Binti Abdul Wahat, Parsa, P. (2014). Relationship between quality of work life and career advancement among Iranian academics. Procedia-Social and Behavioral science, 152, 108-111. DOI: 10.1016/j.sbspro.2014.09.164.

Swamy, D.R., Nanjundeswaraswamy, T.S., \& Rashmi, S. (2015). Quality of Worklife; Development and validation. International Journal of Caring Sciences, 8(2), 281 - 300.
Timossi, L., Pedroso, B., de Francisco, A.C., \& Pilatti, L.A. (2008). Evaluation of quality of work life: an adaptation from the Walton's QWL model. In XIV Intenational Conference on Industrial Engineering and Operations Management. http://pg utfpr edu br/dirppg/ ppgep/ebook/2008/CONGRESSOS/ Internacionais.

Tuomelehto, J., Schwarz, P., \& Lindtrom, J. (2011). Long-term benefits from lifestyle interventions for type 2 diabetes prevention: time to expand the efforts. Diabetes Care, 2, S210-4. DOI: $10.2337 / \mathrm{dc} 11-\mathrm{s} 222$.

Varekamp, I., \& vanDijk, F.J.H. (2010). Workplace problems and solutions for employees with chronic diseases. Occupational Medicine, 60, 287-293. DOI:10.1093/occmed/kqq078.

Vartiainen. E., Jousilahti, P., Alfthan, G., Sundvall, J., Pietinen, P., \& Puska, P. (2000) Cardiovascular risk factor changes in Finland, 1972- 1997. International Journal of Epidemiology, 29, 49-56.

Vuong, T.D., Wei, F., \& Beverly, C.J. (2016). Absenteeism due to functional limitations caused by seven common chronic diseases in US workers. Journal of Occupation Environment Medicine, 57(7), 779-784. DOI:10.1097/JOM.0000000000000452.

World Health Organization [WHO]. (2014). Noncommunicable diseases country profiles. Retrieved from www.who.int/nmh/ publications/ncd-profiles-2014/en.

. (2017). Noncommunicable diseases progress monitor, 2017. Retreived, from http://apps.who.int/iris/bitstream/hand le/10665/258940/9789241513029-eng.pdf;js essionid=389DC05F05D36433BA8EFEA86 22DAC3D? sequence $=1$.

Yu, J., Ma, Y., Yang, S., Pang, K., Yu, Y., Tao, Y., etal.(2015). Risk factors for cardiovascular disease and their clustering among adults in Jilin (China). International Journal of Environmental Research and Public Health, 13, 70. DOI:10.3390/ijerph13010070. 
Titis Kurniawan: Type 2 Diabetes Mellitus Risk Level, Cardiovascular Disease Risk Level

Zatonski, W.A., \& Willett, W. (2005) study. BMJ, 331, 187-188. DOI: https://doi. Changes in dietary fat and declining coronary org/10.1136/bmj.331.7510.187.

heart disease in Poland: Population based 